RECURSOS HUMANOS 


\title{
ESCALA DE COMPETÊNCIAS GERENCIAIS DA ÁREA DA SAÚDE
}

\author{
MANAGEMENT COMPETENCE SCALE IN THE HEATH AREA
}

Adriane Vieira

Universidade Federal de Minas Gerais

Patrícia Lourdes Silva

Universidade Federal de Minas Gerais

Plínio Raphael Reis Monteiro

Universidade Federal de Minas Gerais

Laura Trindade Ituassu

Universidade Federal de Minas Gerais
Fátima Ferreira Roquete

Universidade Federal de Minas Gerais

Data de submissão: 07 abr. 20 | 8. Data de aprovação:

08 set. 20 |8. Sistema de avaliação: Double blind review.

Universidade FUMEC / FACE. Prof. Dr. Henrique Cordeiro

Martins. Prof. Dr. Cid Gonçalves Filho.

\section{RESUMO}

Esta pesquisa tem por objetivo descrever o processo de elaboração e validação de construto de um instrumento utilizado para avaliar as competências de gestores da área da saúde. Na primeira etapa, as competências foram mapeadas com o auxílio de 29 professores da área da saúde. Na segunda etapa, 102 gestores responderam ao questionário. Para a depuração da base, procedeu-se à análise descritiva e multivariada dos dados. Adicionalmente, realizou-se a análise da dimensionalidade, da confiabilidade e da validade da escala, resultando em 20 competências técnicas, distribuídas em cinco eixos temáticos: economia e demografia; política, planejamento e avaliação em saúde; gestão do trabalho e educação em saúde; administração e contabilidade; e metodologias estruturantes. As competências comportamentais mapeadas totalizaram 16 e foram distribuídas nos eixos: idealista/perfeccionista; artesão/negociador' prestativo/ guardião; e motivador/racional.

\section{PALAVRAS-CHAVE}

Gestão. Competências. Saúde. Serviços. Escala. 


\section{ABSTRACT}

This research aimed at describing the process of preparation and the construct validation of an instrument for the assessment of health care managers. In the first step the competences have been mapped with the aid of 29 health professors. In the second stage 102 managers responded to the questionnaire. The descriptive and multivariate data analysis were carried out in order to depurate the base.Additionally, the analysis of dimensionality, reliability and validity of the scale were carried out resulting in 20 technical competences distributed in 5 main themes: Economics and demographics; policy, planning and evaluation in health, management of work and education in health, administration and accounting, and structuring methodologies. Behavioral competencies mapped totaled 16 and were distributed in the themes: idealist/perfectionist, artisan/negotiator, helpful/guardian, and motivator/rational.

\section{KEYWORDS:}

Management. Competencies. Health. Services. Scale.

\section{INTRODUÇÃO}

A forma de gerir vem sofrendo grandes transformações nas últimas décadas, em função da substituição gradual do modelo taylorista/fordista, mecanicista, fechado e centrado na especialização de funções, por um modelo orgânico, flexível e sistêmico de gestão, centrado no trabalho multidisciplinar e descentralizado, com foco no trabalho em equipe e no desenvolvimento de competências técnicas e sociais (RUAS et al., 20I4; SODERQUIST et al., 20I0; NUNES; BARBOSA, 2009).

A economia, cada vez mais globalizada, tem como base de desenvolvimento e crescimento a inovação e o conhecimento, mediante o uso intensivo de tecnologias informacionais, gerando a necessidade de incrementar o investimento em educação continuada, de modo a gestar uma força de trabalho capaz de tomar iniciativas e gerar resultado para as empresas, tornando o capital humano um dos maiores bens (CALHOUN et al., 2008).
Nesse novo contexto, a abordagem das competências ganhou força em todos os setores econômicos, incluindo o da saúde, alvo de atenção por parte de políticos, empresários e pesquisadores em todo o mundo (CHONG, 20I3). Isso ocorre em função das deficiências de custo do sistema, das falhas na qualidade, da baixa satisfação do usuário e das deficiências na educação para as carreiras na área da saúde, em comparação com organizações de outros setores, além da falta de profissionais qualificados para ocuparem cargos gerenciais (CALHOUN et al., 2008; MACKINNON et al., 2004; BUCHAN; DAL POZ, 2002).

A gestão de competências se propõe a integrar os talentos individuais aos objetivos estratégicos organizacionais, estimulando a seleção, a avaliação de desempenho e o desenvolvimento de competências atreladas aos negócios, ao mesmo tempo em que amplia a satisfação de clientes e valoriza seus funcionários. Nessa lógica de ges- 
tão, as pessoas desenvolvem e transferem suas capacidades individuais para os grupos e para a organização, motivadas pelas necessidades de adequação dos serviços e produtos às demandas do mercado e, também, pelo desejo de reconhecimento e de valorização profissional (PERRENOUD, 20 14;BARTH, 2007). Avaliá-las e promover o seu contínuo desenvolvimento são ações estratégicas da área de gestão de pessoas.

O objetivo geral desse trabalho foi descrever o processo de elaboração e validação de construto de um instrumento para análise das competências de gestores da área da saúde, denominada Escala de Competências Gerenciais da Área da Saúde.

Na sequência deste artigo serão apresentados o referencial teórico, que subsidiou a construção da escala, a metodologia utilizada para a elaboração e validação de construto do instrumento, a descrição e análise dos resultados obtidos e as considerações finais.

\section{CONCEITUANDO COMPETÊNCIAS}

Apesar de o tema competência ter sido bastante estudado nas últimas três décadas, ainda existem divergências quanto à sua conceituação (FREITAS; ODELIUS, 2017). Autores norte-americanos, como, McClelland (1973) e Boyatzis (2008), marcaram fortemente a literatura ao sinalizar a importância de alinhar as competências individuais com as necessidades estabelecidas pelos cargos, ou posições existentes na organização. Para eles, as competências são compreendidas como o conjunto de conhecimentos, habilidades e atitudes que justificam um alto desempenho, na medida em que os melhores desempenhos estão fundamentados na inteligência e na personalidade das pessoas (CHONG, 20I3).
Nos anos de 1980, iniciou-se na França o debate a respeito das competências, partindo da crítica ao conceito de qualificação e do processo de formação profissional, principalmente, em função de sua ênfase na formação técnica, centrada nos conhecimentos, e no esquecimento da formação comportamental, centrada nas habilidades e atitudes. Insatisfeitos com a dinâmica entre as necessidades do mundo do trabalho e a mão de obra disponível, os franceses buscaram aproximar o ensino às reais necessidades das organizações, visando melhorar a capacitação dos trabalhadores. Começava-se, então, a articular o campo educacional com o campo das relações de trabalho (CALHOUN et al., 2008).

Para Le Boterf (2003), a competência do indivíduo não é um estado e não se reduz a um conhecimento específico, mas, sim, o resultado do cruzamento de três eixos: a formação da pessoa; sua formação educacional; e sua experiência profissional. 0 conceito ampliado passou a focar também realizações e entregas no contexto em que a pessoa está inserida. Assim, o trabalho não significa mais o conjunto de tarefas associadas descritivamente a um cargo, passando a abranger o prolongamento direto da competência que o indivíduo mobiliza em face de uma situação profissional cada vez mais mutável e complexa (ZARIFIAN, 2005).

As competências gerenciais são consideradas fundamentais caso se deseje obter bons resultados organizacionais, uma vez que são elas que geram e mantêm os diferenciais competitivos (FREITAS; ODELIUS, 2017). Ao investigar as competências de gestores brasileiros de diferentes formações profissionais, como engenharia, psicologia e administração, Godoy e D'Amélio (20I2) identificaram algumas competências 
comuns: a) domínio técnico; b) visão estratégica do negócio; c) gestão orientada para resultados e para clientes internos e externos; d) consciência da complexidade de gerenciar pessoas; e) relacionamento ético e valorativo com stakeholders; e f) capacidade de aprender a aprender. Não obstante, segundo Santos e Honório (2014) a existência de diversas concepções a respeito das competências que o gerente deve desenvolver para atuar em ambientes heterogêneos e ambíguos denota a complexidade do assunto e a necessidade de ele ser mais bem estudado e compreendido.

\section{COMPETÊNCIAS NA ÁREA DA SAÚDE}

No Brasil, a maioria dos cargos gerenciais nos serviços de saúde é ocupada por médicos e enfermeiros (MALIK;TELES, 200I), que aprenderam a coordenar os serviços de maneira empírica. Isso, por si só, já indica a necessidade de investir na formação de um profissional preparado para exercer especificamente tal função.

Para ser um gestor de serviços de saúde, segundo Seixas e Melo (2004) é necessário saber coordenar as atividades, para: atingir objetivos; promover programas de capacitação dos profissionais, para acompanhar as inovações; e promover a motivação do pessoal, para que trabalhe com entusiasmo. Em síntese, a responsabilidade maior do gestor é proporcionar o bom desenvolvimento das diversas atividades técnicas e profissionais, que são realizadas ao mesmo tempo, visando atender às necessidades de assistência e promoção da saúde das populações, de modo a agir, mobilizar e transferir conhecimentos para resolver situações práticas de acordo com a área de atuação (MANENTTI et al., 20I2).
Como consequência da ampliação da cobrança da sociedade por uma maior responsabilidade social, por parte dos profissionais da área da saúde, e maior equilíbrio entre custos, acesso e qualidade do atendimento, o tema competências vem ocupando espaço cada vez mais expressivo nas políticas institucionais e na academia (FRAGELLI; SHIMIZU, 20I2; MANENTTI et al., 2012; CALHOUN et al. 2008; BUCHAN; DAL POZ, 2002).

Algumas dessas competências, identificadas por Hilbert, Duarte e Milaré (20II), envolvem: automonitoramento; capacidade de trabalhar em equipe; comprometimento; comunicação; resiliência; e capacidade de resolver conflitos.

Dias e Paiva (20II) acrescentam: necessidade de conhecimento do mercado; visão estratégica e conhecimento sobre tecnologia de sistemas; gerenciamento do desempenho humano e financeiro do negócio; análise e síntese para a tomada de decisão; adaptabilidade; e disposição para mudança.

Conclui-se que o gestor da área de saúde deve desenvolver competências de natureza tanto técnica quanto comportamental. A primeira estaria relacionada às habilidades operacionais, englobando os conhecimentos de que o profissional precisa dominar para desempenhar sua função. A segunda engloba as habilidades e as atitudes; ou seja, tudo aquilo que o profissional precisa demonstrar como seu diferencial competitivo e que tem impacto em seus resultados, por exemplo, criatividade, flexibilidade, foco em resultados e no cliente e liderança (MANFREDI, 1999).

\section{METODOLOGIA DA PESQUISA}

Esta pesquisa foi aprovada pelo Comitê de Ética em Pesquisa, CAAE 029487/2.0.0000.5I49. 
Os participantes do estudo assinaram o Termo de Consentimento Livre e Esclarecido, após receberem esclarecimentos quanto aos objetivos da pesquisa.

Seguindo as orientações de Costa (20II), para a construção da Escala de Competências Gerenciais da área da saúde utilizou-se uma série de procedimentos qualitativos e quantitativos. Na primeira etapa, as competências foram mapeadas com a ajuda de especialistas da área, para conformá-las aos itens da escala. $\mathrm{Na}$ segunda etapa, a escala foi submetida à análise quantitativa, contando-se com a resposta de 102 gestores da área da saúde, com o objetivo de depurar as medições. Os dados coletados foram analisados, com a finalidade de ajustar o instrumento de medição em questão. Na sequência do trabalho, cada uma dessas etapas será descrita em detalhes.

\section{Primeira etapa}

Foram convidados a participar do mapeamento das competências 29 professores da Universidade Federal de Minas Gerais que ministram disciplinas obrigatórias e optativas no curso de Gestão de Serviços de Saúde.Todos foram contatados via mensagem eletrônica e/ou telefone, para agendamento de entrevistas. Todavia, diante da dificuldade para compatibilizar as agendas e dos sucessivos cancelamentos e remarcações, optou-se por enviar formulário contendo duas perguntas: $O$ que você espera que o aluno seja capaz de fazer após ter cursado sua disciplina? Quais comportamentos deve apresentar $\bigcirc$ aluno que aprendeu o conteúdo que era previsto?

As respostas escritas foram enviadas eletronicamente aos pesquisadores. As competências descritas pelos foram listadas e agrupadas em 'técnicas' e 'compor- tamentais', conforme classificação de Manfredi (1999).

As competências técnicas foram agrupas nos seguintes eixos temáticos:

- Economia e demografia - envolve noções básicas da moderna economia capitalista global, conhecimento da avaliação econômica da tecnologia, terapias e medicamentos nos diversos segmentos da saúde e fundamentos microeconômicos do mercado de bens e serviços de saúde.

- Política, planejamento e avaliação em saúde - envolve compreensão das políticas sociais e de saúde, planejamento de sistemas e serviços de saúde, organização de redes de atenção e avaliação de políticas, programas e práticas de saúde.

- Gestão do trabalho e educação em saúde - envolve o planejamento e a organização dos processos de trabaIho, pautados no trabalho em equipe, na qualidade e acreditação, na educação em saúde e na introdução de novas tecnologias.

-Administração e contabilidade - envolve as ferramentas e técnicas de planejamento, organização e gerenciamento dos recursos tangíveis e intangíveis, contemplando os recursos materiais, patrimoniais, financeiros, orçamentários, de pessoal e de informação.

- Metodologias estruturantes - envolve o conhecimento das metodologias de pesquisa científica necessário à construção de projetos e à análise e interpretação dos resultados de pesquisas. As competências comportamentais foram mapeadas e agrupadas em quatro eixos temáticos, a saber:

- Idealista/perfeccionista - envolve a ca- 
pacidade de examinar fatos, situações e pessoas. Preza o planejamento e a organização, bem como o respeito às regras e normas. Valoriza a criatividade e a inovação.

- Artesão/negociador - envolve a habilidade de lidar com as pessoas, conciliar interesses e resolver conflitos. Requer liderança e rapidez na ação, além da capacidade de interação e colaboração. Propicia flexibilidade e liberdade para a criação de soluções. Enfatiza a produção de resultados e produtos.

- Prestativo/guardião - envolve a valorização do trabalho e da rotina. Prioriza segurança e estabilidade, atenção a fatos e detalhes, seriedade, colaboração, facilidade para o trabalho em equipe e sensibilidade para com o outro.

- Motivador/racional - envolve a capacidade de raciocínio e de dedução lógica. Demanda profissionais observadores e determinados, que gostem de aprender e saibam se expressar com fluência, autossuficiência, capacidade de adaptação, comunicação, debate e planejamento.

Com respaldo em Pasquali (2010) e Netemeyer et al. (2003), os itens do instrumento foram submetidos à avaliação de um painel de especialistas, que contou com a participação de 10 gestores de serviços de saúde, para julgamento da clareza da linguagem e da pertinência dos itens do questionário. Não foi constatada a necessidade de adequação. Posteriormente, foram agregadas ao questionário indagações sobre dados sociodemográficos e funcionais. $\mathrm{Na}$ sequência, aplicou-se o pré-teste do instrumento com 10 estudantes do curso de graduação, não tendo sido realizadas mudanças significativas.
A versão final do questionário elaborado continha a seguinte orientação: "Neste questionário, você deve perguntar a si próprio: Quais são as competências importantes para realizar o meu trabalho? A seguir, há uma lista de competências. Pedimos que você analise o quão importante cada competência é para você como um indicador de seu bom desempenho profissional. Marque uma resposta que indique a sua opinião, conforme a escala a seguir".

Para mensurar o grau de importância das competências, adotou-se uma escala likert de 5 pontos ( $I$ = 'nada importante'; 2 = 'pouco importante'; 3 = 'importante; 4 = 'muito importante; e 5 = 'extremamente importante').

\section{Segunda etapa}

O método survey foi escolhido para a realização da pesquisa de campo, e os dados foram coletados em um único ponto no tempo (cross-sectional) (BABBIE, I 999).

A população do estudo contemplou gestores da área da saúde inseridos em organizações localizadas na grande Belo Horizonte. Para acessá-los, contou-se com indicações dos professores e supervisores de estágio do curso de graduação em Gestão de Serviços de Saúde.

Foram convidados a participar da pesquisa gestores de organizações públicas e privadas de diversos segmentos, com a finalidade de compor uma amostra heterogênea, tais como: hospital público, hospital privado, clínica médica, clínica de medicina do trabalho, laboratório clínico, centro de pesquisa, secretaria de saúde municipal, secretaria de saúde estadual, unidade básica de saúde, unidade de pronto atendimento, clínica de imagem e empresa de auditoria.

Foram distribuídos 130 questionários e 
obtidas 102 respostas. Definiu-se como critério de inclusão: o respondente ocupar cargo de gestão em serviços de saúde há pelo menos seis meses. $\bigcirc$ critério de exclusão foi: o respondente não atender ao requisito citado anteriormente. Após a entrega do questionário, foi estabelecido um período de trinta dias, com uma tentativa de recoIhimento do instrumento a cada dez dias, totalizando três tentativas por questionário, sendo que o não recolhimento do instrumento neste período o invalidava.

\section{RESULTADOS DAS ANÁLISES PRELIMINARES DO BANCO DE DADOS}

Os dados dos questionários foram tabulados em planilha e analisados por meio do software IBM SPSS (Statistical Packege for the Social Science) versão $20.0 \AA$, e Smartpls 2.I e Microsoft Excel@, utilizando-se a estatística descritiva e multivariada.

Conforme sugere a literatura (HAIR et al., 2007, 20I0; KLINE, 2005;TABACHNICK; FIDELL, 2007), precedeu- se à verificação das premissas requeridas pela análise de dados do estudo. Os dados ausentes na pesquisa foram mínimos: 13 respostas ausentes $(0,121 \%$ da base) do total de 10.710 (102 questionários x 105 variáveis). Dado que os valores são bastante inferiores a qualquer potencial preocupante (5\%), optou-se por repor estes dados pela média aritmética simples. Os outliers univariados foram classificados como respondentes com respostas fora dos padrões dos quartis $(\mathrm{Q} I$ - I.5*IQR, $\mathrm{Q} 3+1.5 * \mathrm{QQR})$, sendo encontrados 74 valores negativos e 33 valores positivos, os quais foram mantidos na análise.

Os outliers multivariados foram classificados pelo método da distância, de Mahalanobis $\left(\mathrm{D}^{2}\right)$, divididos pelo número de variáveis. Os casos em que a estatística ultrapassasse o valor de dois (2) seriam classificados como outliers multivariados. Porém, nem um caso deste tipo ocorreu, mesmo quando se dividiu a amostra nos diferentes blocos da pesquisa para o cálculo da estimativa.

Para a análise da normalidade, procedeuse ao cálculo das estimativas de assimetria e curtose, bem como ao emprego do teste de Jarque-Bera. No caso das estimativas de assimetria, encontraram-se 17 valores fora do intervalo de \pm I (MUTHEN; KAPLAN, 1992), sendo 32 significativos. Para a curtose, I I valores ficaram fora do intervalo proposto (4 significativos), em que 38 variáveis foram consideradas não normais pelo teste Jarque-Bera. Em que pese ao reduzido tamanho da amostra, apesar dos desvios encontrados, não se acredita que o desvio da normalidade seja problemático para a pesquisa.

Para balizar a linearidade, foram traçados diagramas de dispersão entre 30 pares de variáveis, buscando analisar desvios aparentes da linearidade. Porém, nem um foi detectado. Para verificar a adequação do instrumento de pesquisa, procedeu-se à avaliação da dimensionalidade das escalas, das medidas de qualidade da mensuração e, por fim, da validade de construto (NETEMEYER; BEARDEN; SHARMA, 2003). Em primeiro lugar, foi realizada a etapa de redução de dados, aplicando-se a AFE para cada competência, considerando sua possibilidade de desenvolvimento em diferentes áreas do curso.

Para melhor compreensão dos resultados da pesquisa, a Tabela I mostra a organização e distribuição das competências técnicas nos cinco eixos temáticos, a fim de evidenciar que algumas delas são comuns a mais de um eixo. 
TABELA 1 - Competências técnicas por eixos temáticos

\begin{tabular}{|c|c|c|c|c|c|}
\hline \multirow{2}{*}{ Competências técnicas } & \multicolumn{5}{|c|}{ Eixos temáticos } \\
\hline & A & B & C & D & E \\
\hline Administração e contabilidade & & & & D1 & \\
\hline Análise crítica & A5 & B6 & C7 & D8 & E4 \\
\hline Gestão de processos & A3 & B4 & C5 & & \\
\hline Elaboração de políticas & A9 & B10 & $\mathrm{C} 11$ & & \\
\hline Gestão de custo & & & & D4 & \\
\hline Gestão financeira & & & & D3 & \\
\hline Medidas em demografia & A11 & & & & \\
\hline Conhecimentos de políticas de saúde & A6 & B7 & C8 & & \\
\hline Promoção de saúde e equidade & A10 & & $\mathrm{C} 12$ & & \\
\hline Sistemas de informação & A8 & B9 & $\mathrm{C} 10$ & D10 & E6 \\
\hline Fundamentos de pesquisa científica & & B2 & C3 & & E2 \\
\hline Economia da saúde & A1 & & & & \\
\hline Educação em saúde & & & $\mathrm{C} 2$ & $\mathrm{D} 2$ & \\
\hline Gestão do trabalho & & & C1 & & \\
\hline Metodologias estruturantes & & & & & E1 \\
\hline Otimização de recursos & & & & D5 & \\
\hline Planejamento estratégico & A2 & B3 & C4 & D6 & \\
\hline Planejamento e avaliação em saúde & & B1 & & & \\
\hline Raciocínio lógico & A7 & B8 & C9 & D9 & E5 \\
\hline Visão sistêmica & A4 & B5 & $\mathrm{C} 6$ & D7 & E3 \\
\hline
\end{tabular}

Fonte: dados da pesquisa.

Notas: Eixos: A = "Economia e demografia'; B = 'Política, planejamento e avaliação em saúde'; C = 'Gestão do trabalho e da educação em saúde'; D = 'Administração e contabilidade'; E = 'Metodologias estruturantes'.

\section{RESULTADOS}

\section{Análise fatorial}

Com base na Tabela I, seguiu-se a avaliação descritiva dos itens. Inicialmente, cada competência foi reduzida a uma única variável, calculando-se a média aritmética simples dos itens. Para isso, testou-se a dimensionalidade dos itens nos casos em que existiam mais de uma avaliação da competência em diferentes eixos. Aplicando-se a AFE com extração por componentes principais (rotação varimax), apurou-se que todas as competências puderam ser classificadas como unidimensionais. Neste caso, procedeu-se ao cálculo da média aritmética simples dos indicadores.
Após a primeira aplicação da AFE, aplicouse uma segunda rodada, para reduzir as competências a grupos de fatores (Tabela 2).

Os resultados mostram o agrupamento das competências em cinco eixos temáticos, com resultados favoráveis à aplicação da técnica. $\bigcirc$ mesmo procedimento foi aplicado às competências comportamentais. Inicialmente, foram calculadas as médias dos indicadores de competências comportamentais, que serão apresentados na sequência deste trabalho (Tabela 5). Em seguida, aplicou-se a AFE aos indicadores nos quatro eixos temáticos (Tabela 3 ).

Por fim, testou-se um modelo de Análise Fatorial Confirmatória (AFC), utili- 
TABELA 2 - Análise fatorial exploratória das competências técnicas

\begin{tabular}{|c|c|c|c|c|c|}
\hline \multirow{2}{*}{ Competências técnicas } & \multicolumn{5}{|c|}{ Eixos temáticos } \\
\hline & A & B & C & D & E \\
\hline Planejamento e avaliação em saúde & 0,83 & 0,08 & $-0,07$ & 0,28 & 0,06 \\
\hline Promoção de saúde e equidade & 0,82 & $-0,09$ & 0,07 & $-0,08$ & 0,20 \\
\hline Conhecimentos de políticas de saúde & 0,78 & 0,03 & $-0,01$ & $-0,09$ & 0,07 \\
\hline Elaboração de políticas & 0,70 & 0,07 & $-0,22$ & $-0,07$ & $-0,23$ \\
\hline Fundamentos de pesquisa científica & 0,47 & 0,04 & 0,04 & $-0,43$ & 0,29 \\
\hline Medidas em demografia & 0,46 & 0,06 & $-0,15$ & $-0,40$ & $-0,18$ \\
\hline Gestão de custo & 0,10 & 0,94 & 0,04 & 0,03 & $-0,03$ \\
\hline Gestão financeira & 0,11 & 0,93 & 0,02 & $-0,04$ & $-0,07$ \\
\hline Administração e contabilidade & $-0,08$ & 0,86 & 0,03 & $-0,09$ & $-0,02$ \\
\hline Otimização de recursos & $-0,11$ & 0,69 & $-0,30$ & 0,11 & 0,14 \\
\hline Planejamento estratégico & $-0,03$ & 0,05 & $-0,87$ & $-0,01$ & 0,03 \\
\hline Gestão de processos & 0,00 & $-0,01$ & $-0,86$ & $-0,05$ & 0,07 \\
\hline Visão sistêmica & 0,08 & 0,06 & $-0,85$ & 0,08 & 0,07 \\
\hline Análise crítica & 0,07 & 0,01 & $-0,82$ & $-0,05$ & 0,01 \\
\hline Economia da saúde & $-0,06$ & 0,15 & 0,09 & $-0,78$ & 0,06 \\
\hline Sistemas de informação & 0,09 & $-0,12$ & $-0,35$ & $-0,63$ & $-0,04$ \\
\hline Raciocínio lógico & 0,09 & 0,10 & $-0,34$ & $-0,45$ & 0,06 \\
\hline Gestão do trabalho & 0,08 & $-0,11$ & $-0,18$ & 0,11 & 0,86 \\
\hline Educação em saúde & $-0,07$ & 0,20 & $-0,21$ & $-0,28$ & 0,51 \\
\hline Metodologias estruturantes & 0,25 & 0,23 & 0,06 & $-0,20$ & 0,44 \\
\hline Auto valor & 8,0 & 2,3 & 1,8 & 1,2 & 1,1 \\
\hline Variância explicada (\%) & 40,1 & 11,6 & 8,8 & 5,8 & 5,4 \\
\hline Variância acumulada (\%) & 40,1 & 51,7 & 60,5 & 66,4 & 71,8 \\
\hline
\end{tabular}

Fonte: dados da pesquisa.

Notas: $\mathrm{KMO}=$ 0,838. Ponto de corte de significância das cargas fatoriais de 0,400. Eixos: $\mathrm{A}=$ "'Economia e Demografia'; $\mathrm{B}=$ 'Política, planejamento e avaliação em saúde'; C = 'Gestão do trabalho e da educação em saúde'; D = 'Administração e contabilidade'; E = 'Metodologias estruturantes'.

zando-se a abordagem Parcial Least Square (PLS), bastante robusta a desvios da normalidade e aplicável em casos de pequenas amostras. $O$ modelo foi operacionalizado com fatores de segunda ordem pelo método da média dos indicadores de primeira ordem (VINZI; TRINCHERA; AMATO, 2010). Após essa operacionalização, procedeu-se à avaliação da validade de construto, por meio do método da significância das cargas fatoriais, considerando um nível de $5 \%$ bicaudal. Foi necessário excluir os indicadores com valores $T$ inferiores a 1,64 , pois não alcançaram validade convergente mínima. Após essa exclusão, as medidas de confiabilidade e de validade das medidas foram calculadas.

\section{Caracterização da amostra}

Os 102 respondentes eram majoritariamente do sexo feminino (67\%); $97 \%$ da amostra possuía nível superior, sendo $59 \%$ com título de mestre e $3 \%$ de doutor. Do restante da amostra, I\% possuía nível técnico e $2 \%$, ensino médio completo. Dentre os profissionais de nível superior, $27 \%$ eram graduados em Enfermagem, 18\% em Gestão de Serviços de Saúde, 17\% em Administração, I4\% em Medicina, 6\% em Psicologia, I\% em Fisioterapia e 17\% em outros cursos. 
TABELA 3 - Análise fatorial exploratória da competências comportamentais

\begin{tabular}{|c|c|c|c|c|}
\hline \multirow{2}{*}{ Competências comportamentais } & \multicolumn{4}{|c|}{ Eixos temáticos } \\
\hline & $\mathbf{F}$ & G & $\mathbf{H}$ & $\mathbf{I}$ \\
\hline Disciplina & 0,62 & 0,08 & 0,16 & 0,07 \\
\hline Criatividade & 0,52 & $-0,17$ & 0,11 & $-0,34$ \\
\hline Comunicação & 0,49 & 0,13 & $-0,04$ & $-0,20$ \\
\hline Ética & 0,49 & 0,14 & 0,04 & 0,18 \\
\hline Inovação & 0,48 & $-0,07$ & 0,13 & $-0,26$ \\
\hline Autoconfiança & 0,48 & $-0,20$ & $-0,01$ & $-0,31$ \\
\hline Trabalho em equipe & 0,02 & 0,62 & 0,35 & $-0,09$ \\
\hline Negociação & 0,34 & 0,54 & $-0,13$ & $-0,23$ \\
\hline Flexibilidade & $-0,06$ & $-0,07$ & 0,80 & $-0,07$ \\
\hline Manter-se atualizado & 0,12 & 0,32 & 0,48 & 0,01 \\
\hline Escuta crítica e acolhedora & 0,24 & 0,02 & 0,44 & $-0,05$ \\
\hline Proatividade & $-0,04$ & 0,05 & 0,16 & $-0,77$ \\
\hline Resiliência & $-0,02$ & 0,03 & 0,06 & $-0,69$ \\
\hline Motivação & 0,17 & 0,37 & 0,04 & $-0,45$ \\
\hline Tomada de decisão & 0,17 & 0,28 & 0,15 & $-0,36$ \\
\hline Relacionamento interpessoal & 0,35 & 0,25 & $-0,03$ & $-0,36$ \\
\hline Auto valor & 6,7 & 0,9 & 0,8 & 0,5 \\
\hline Variância explicada (\%) & 39,3 & 5,4 & 4,9 & 3,1 \\
\hline Variância acumulada (\%) & 39,3 & 44,7 & 49,6 & 52,6 \\
\hline
\end{tabular}

Fonte: dados da pesquisa.

Notas: $\mathrm{KMO}=0,858$. Ponte de corte de significância das cargas fatoriais de 0,400. Eixos: $\mathrm{F}=$ 'Idealista/Perfeccionista'; $\mathrm{G}=$ 'Artesão/ Negociador'; H = 'Prestativo/Guardião'; I = 'Motivador/Racional'.

\section{Importância das competências técnicas}

As competências técnicas têm como base os conhecimentos adquiridos na formação profissional e exigem o desenvolvimento de habilidades operacionais e a capacidade do indivíduo em lidar com as forças de dentro e de fora das organizações (MANFREDI, 1999).

A análise das médias obtidas por eixo (Tabela 4) revelou que 'Administração e contabilidade' e 'Política, planejamento e avaliação em saúde' foram as competências que obtiveram médias mais altas $(4, I)$, sendo consideradas as mais importantes para o desempenho profissional dos gestores. Na sequência, aparecem: 'Economia e demografia' e 'Gestão do trabalho e da educação', ambas com média 4,0. 0 eixo 'Metodologias estruturantes' obteve média
3,9. Destaca-se que a diferença de pontuação entre os eixos foi muito pequena, sendo notório que as competências técnicas são consideradas 'muito importantes' para o bom desempenho profissional.

A análise das médias de todas as competências, independentemente do eixo, revelou que as competências que receberam nota 4,0 ou mais, ocupando as posições 'muito importante' e 'extremamente importante', em ordem decrescente, foram: 'Planejamento estratégico'; 'Elaboração e gestão de projetos'; 'Visão sistêmica'; Análise crítica'; 'Otimização de recursos'; 'Planejamento e avaliação em saúde'; 'Gestão do trabalho e da educação em saúde'; 'Políticas de saúde'; 'Raciocínio lógico'; e 'Gestão de custos'.

As demais competências obtiveram mé- 
TABELA 4 - Média de importância das competências técnicas

\begin{tabular}{l|c|c|c|c|c|c}
\hline \multicolumn{1}{c|}{ Competências técnicas } & \multicolumn{5}{c|}{ Eixos temáticos } & \multicolumn{2}{c}{ Média } \\
\hline & A & B & C & D & E & \\
\hline Planejamento estratégico & 4,6 & 4,5 & 4,4 & 4,5 & & 4,5 \\
\hline Gestão de processos & 4,5 & 4,4 & 4,3 & & & 4,4 \\
\hline Visão sistêmica & 4,6 & 4,5 & 4,4 & 4,5 & 4,1 & 4,4 \\
\hline Análise crítica & 4,5 & 4,4 & 4,4 & 4,4 & 4,2 & 4,4 \\
\hline Otimização de recursos & & & & 4,3 & & 4,3 \\
\hline Planejamento e avaliação em saúde & & 4,2 & & & & 4,2 \\
\hline Gestão do trabalho & & & 4,1 & & & 4,1 \\
\hline Conhecimento das políticas em saúde & 4,0 & 4,1 & 4,0 & & & 4,0 \\
\hline Raciocínio lógico & 4,0 & 3,9 & 3,9 & 4,1 & 3,9 & 4,0 \\
\hline Gestão de custo & & & & 4,0 & & 4,0 \\
\hline Administração e contabilidade & & & & 3,9 & & 3,9 \\
\hline Gestão financeira & & & & 3,9 & & 3,9 \\
\hline Sistemas de informação & 3,8 & 3,8 & 3,8 & 3,9 & 3,8 & 3,8 \\
\hline Promoção da saúde e equidade & 3,8 & & 3,9 & & & 3,8 \\
\hline Educação em saúde & & & 4,0 & 3,6 & & 3,8 \\
\hline Elaboração de políticas em saúde & 3,7 & 3,8 & 3,8 & & & 3,7 \\
\hline Metodologias estruturantes & & & & & 3,7 & 3,7 \\
\hline Economia e demografia & 3,5 & & & & & 3,5 \\
\hline Fundamentos de pesquisa científica & & 3,3 & 3,5 & & 3,5 & 3,5 \\
\hline Medidas em demografia & 3,1 & & & & & 3,1 \\
\hline Média & $\mathbf{4 , 0}$ & $\mathbf{4 , 1}$ & $\mathbf{4 , 0}$ & $\mathbf{4 , 1}$ & $\mathbf{3 , 9}$ & $\mathbf{4 , 0}$ \\
\hline Fon da & & & & \\
\hline
\end{tabular}

Fonte: dados da pesquisa.

Notas: eixos: $\mathrm{A}$ = 'Economia e demografia'; $\mathrm{B}$ = 'Política, planejamento e avaliação em saúde'; C = 'gestão do trabalho e da educação em saúde'; $D$ = 'Administração e contabilidade'; E = 'Metodologias estruturantes'.

dias entre 3, I e 3,9, sendo que 'Medidas em demografia' obteve a menor média $(3, I)$, ficando quatro décimos $(0,4)$ abaixo da penúltima colocada e I,4 ponto abaixo da primeira colocada.

Observou-se, também, que a nota dada ao próprio eixo, destacada em itálico na Tabela 4, obteve média inferior à média geral das competências do eixo. O eixo 'Economia e demografia', por exemplo, obteve média 3,5 e a média de todas as competências do eixo foi $4, \mathrm{I}$. Isso aconteceu porque o respondente avaliava primeiro a importância do eixo e depois a importância das competências que compunham o eixo.
O eixo 'Política, planejamento e avaliação em saúde', recebeu média 4,2, enquanto a média geral das competências do eixo foi 4,I. O eixo 'Gestão do Trabalho e educação em saúde' obteve média $4, I$, enquanto a média geral das competências do eixo foi 4,0. O eixo 'Administração e contabilidade' obteve média 3,9, e a média geral das competências do eixo foi 4,I. Por fim, o eixo 'Metodologias estruturantes', obteve média 3,7 e a média geral das competências do eixo foi 3,9.

As análises das médias de importância do eixo temático 'Economia e demografia' colocam em destaque as competências: 
'Planejamento estratégico' (4,6); 'Visão sistêmica' $(4,6)$; 'Elaboração e gestão de projetos' $(4,5)$; e 'Análise crítica' $(4,5)$. Nas duas últimas posições ficaram: 'Economia' $(3,5)$ e 'Medidas em demografia' $(3,1)$.

Dentre as competências do eixo 'Política, planejamento e avaliação em saúde', 'Planejamento estratégico' recebeu a maior média $(4,5)$, seguida de 'Análise crítica' $(4,5)$. As competências 'Elaboração e gestão de projetos' e 'Análise crítica', ficaram empatadas em segundo lugar $(4,4)$. A menos importante foi 'Fundamentos de pesquisa científica' $(3,3)$.

Comparativamente ao eixo anterior (Economia e demografia), as competências técnicas em destaque neste eixo (Política, planejamento e avaliação em saúde) obedeceram à mesma ordem de ranqueamento. A diferença que se pode destacar é que 'Políticas de saúde' recebeu diferença positiva de I (um) décimo, no último eixo citado; e 'Planejamento e avaliação em saúde', que pertence apenas a este último eixo, obteve média 4,2 .

Dentre as competências deste eixo, ficaram empatadas em primeiro lugar $(4,4):{ }^{\prime} \mathrm{Vi}$ são sistêmica', 'Planejamento estratégico' e 'Análise crítica'. Em segundo lugar ficou 'Elaboração e gestão de projetos'. Enquanto 'Fundamentos de pesquisa científica' ficou em último lugar, com média 3,5.

No eixo 'Administração e contabilidade' as competências 'Planejamento estratégico' e 'Visão sistêmica' obtiveram a média mais alta: 4,5. Situou-se em segundo lugar 'Análise crítica' $(4,4)$, e em terceiro 'Otimização de recursos' $(4,3)$. A competências 'Educação em saúde' $(3,6)$ obteve a menor média.

No eixo 'Metodologias estruturantes', as competências 'Análise crítica' $(4,2)$ e 'Visão sistêmica' $(4, I)$, obtiveram as médias mais altas, sendo consideradas a 'muito importantes' para o desempenho profissional dos gestores nesta área. Já 'Fundamentos de pesquisa científica' $(3,5)$ obteve a menor média. No intermédio, ficaram as competências 'Raciocínio lógico' $(3,9)$ e 'Sistemas de informação' $(3,8)$.

\section{Importância das competências comportamentais}

Segundo Leme (2005, p. 3), competência comportamental traduz a capacidade de contatar, integrar e identificar as próprias emoções, motivações e pensamentos, vivenciando-os e gerenciando-os conscientemente, para expressá-los eficazmente na forma de comportamentos e atitudes que garantam mais satisfação e realizações em sua vida profissional e pessoal. De acordo com os dados da Tabela 5, todas as competências comportamentais receberam média acima de 4,0.

'Ética' foi a competência que obteve a média mais alta $(4,7)$. Em segundo lugar ficaram as competência que receberam média 4,6: 'Trabalho em equipe'; 'Tomada de decisão'; 'Relacionamento interpessoal'; e 'Manter-se atualizado'. Em terceiro ficaram as competências: 'Comunicação'; 'Proatividade'; e 'Escuta crítica e acolhedora'. A competência 'Inovação' ficou em último lugar. As médias por eixo mostraram pouca variação.

\section{DISCUSSÃO}

A competência técnica 'Planejamento estratégico' foi considerada a mais importante para os gestores da área da saúde, presente em praticamente todos os eixos, exceto no 'Metodologias estruturantes', comprovando a existência de competências do tipo multidisciplinares. 
TABELA 5 - Média de importância das competências comportamentais por eixos

\begin{tabular}{l|c}
\hline Competências comportamentais & Média \\
\hline Ética & 4,7 \\
\hline Comunicação & 4,5 \\
\hline Disciplina & 4,4 \\
\hline Criatividade & 4,2 \\
\hline Inovação & 4,1 \\
\hline Autoconfiança & 4,3 \\
\hline Idealista/perfecionista & 4,4 \\
\hline Trabalho em equipe & 4,6 \\
\hline Negociação & 4,3 \\
\hline Artesão/negociador & 4,4 \\
\hline Tomada de decisão & 4,6 \\
\hline Relacionamento interpessoal & 4,6 \\
\hline Proatividade & 4,5 \\
\hline Motivação & 4,4 \\
\hline Resiliência & 4,2 \\
\hline Motivador/racional & 4,5 \\
\hline Manter-se atualizado & 4,6 \\
\hline Escuta crítica e acolhedora & 4,5 \\
\hline Flexibilidade & 4,3 \\
\hline Prestativo/guardião & 4,5 \\
\hline Média & $\mathbf{4 , 4}$ \\
\hline
\end{tabular}

Fonte: dados da pesquisa.

Outro ponto a se destacar é que todas as competências técnicas mapeadas foram consideradas pelos gestores como importantes, uma vez que nem uma delas obteve média abaixo de 3,0 . Isso revela como a formação do profissional deve ser realizada com base em uma ampla gama de conhecimentos, provenientes tanto da área da saúde quanto das ciências sociais aplicadas, devido à complexidade deste setor da economia. Cabe, portanto, ao gestor incorporar continuamente novas tecnologias que propiciem resolutividade e melhorar a qualidade do cuidado, mediante a minimização dos riscos assistenciais e financeiros (CARDOSO; SERRALVO, 2009; CALHOUN et al., 2008; HOKERBERG et al., 2006; SCHOUT; NOVAES, 2007).

Como alertam Mackinonn et al. (2004), a complexidade da área da saúde requer dos gestores o domínio de competências diferentes, necessárias para liderar em ambientes de mudanças. Por esse motivo, a atividade gerencial passou a incorporar em seus processos os princípios da eficácia, efetividade, qualidade total e excelência, próprios das demais áreas da economia, em especial da indústria, a fim de alcançar objetivos, metas e resultados organizacionais (MANENTTI et al., 20I2).

A partir da análise por eixo temático, depreende-se que as competências do eixo 'Política, planejamento e avaliação em saúde' contribuem para que o gestor seja capaz de elaborar estratégias que melhorem as desigualdades em saúde e para que os vínculos com instituições acadêmicas sejam expandidos, engajando todos os envolvidos no planejamento e nas avaliações em todos os níveis (CARBONI; REPPETTO, 2007). 
Tratar a implementação de políticas de saúde como objeto de investigação pressupõe desvendar os modos pelos quais ocorrem as conexões entre a formulação de diretrizes políticas e sua operacionalização nos serviços de saúde. As conexões referidas podem estar mediadas pelo planejamento estratégico, como parte importante da gestão dos sistemas e serviços de saúde (VILASBOAS; PAIM, 2008), por se tratar de um procedimento sistemático de tomada de decisão (PERERA; PEIRÓ, 20I2).

O eixo 'Administração e contabilidade', que também ocupa o primeiro lugar, aborda conhecimentos e instrumentos de gestão disponíveis para atuar no planejamento, organização e gerenciamento dos processos de trabalho das instituições de saúde. De acordo com Fernandes, Machado e Anschau (2009), no atual contexto econômico essas atividades ganham nova ênfase, exigindo dos gestores competências técnicas mais amplas, que congreguem os conhecimentos da assistência à saúde com aqueles próprios da administração, da economia e da contabilidade.

$\mathrm{Na}$ área da saúde, as mudanças no perfil de competências dos profissionais visam atender às necessidades de assistência e promoção da saúde das populações, demandando que eles saibam agir, mobilizar, transferir conhecimentos para resolver situações práticas, aprender constantemente e engajar-se em resposta às exigências e necessidades de cada área de atuação (MANENTTI et al., 20I2). É importante lembrar que, com a descentralização do SUS, a função gerencial passou a assumir grande importância, pela necessidade de liderar a reorganização dos processos de trabalho, para o efetivo funcionamento das políticas públicas. Nesse contexto, o desen- volvimento de competências relacionadas ao planejamento e à avaliação de serviços se torna vital para os futuros profissionais da área (BATISTA-SIQUEIRA et al., 20I3).

No eixo 'Gestão do trabalho e da educação em saúde' (média geral 4,0), a valorização da competência 'Educação' $(4, I)$ confirma a importância dos programas de capacitação profissional para a eficácia do cuidado, da prevenção e da promoção da saúde, permitindo a redução dos gastos futuros com tratamentos de alta complexidade.Vale ressaltar, também, que as tendências do trabalho em saúde apontam para uma formação mais polivalente, no sentido da multiqualificação, gerando a necessidade de rever o conteúdo das atuais formações de nível médio, técnico e superior, de modo a fornecer conteúdos teóricos e práticos que fortaleçam a integração entre equipes multiprofissionais, paciente e processos institucionais (LASCHINGER; SMI$\mathrm{TH}, 20 \mathrm{I}$ ).

Segundo Almeida, Borba e Flores (2009), a saúde é uma área bastante complexa, na medida em que se compõe de vários tipos de procedimentos e atividades. Isso torna sua administração uma tarefa desafiadora. A gestão de custos, em especial, segundo os autores, se revela útil em qualquer tipo de organização e proporciona ao administrador uma visão mais acurada e ampliada da realidade financeira, já que permite olhar por outro ângulo como são gastos os recursos disponíveis, permitindo identificar os exageros e destinar os recursos na quantidade certa para serem aplicados nas atividades mais necessárias.

Entende-se que apesar de a competência técnica 'Medidas em demografia', pertencente ao eixo 'Economia e demografia' (média geral 4,0), ter apresentado a menor 
média $(3, I)$, ela contribui para que o gestor tenha uma visão sistêmica, crítica e contextualizada dos serviços de saúde, devido às significativas mudanças na pirâmide populacional brasileira. $O$ crescimento da população de idosos (pessoas acima dos 60 anos de idade), em números absolutos e relativos, é um fenômeno mundial (NOGUEIRA et al., 2008). Devido a essa transição, doenças infectocontagiosas, altamente prevalentes em populações jovens, tendem a diminuir sua incidência, ao passo que as doenças crônicas não transmissíveis, próprias do processo de envelhecimento, aumentam sua prevalência (ALVES et al., 2007).

O eixo 'Metodologias estruturantes' foi considerado o menos importante. No entanto, cabe alertar que o desconhecimento sobre metodologias de pesquisa pode levar a avaliações superficiais e rotulagens que prejudicarão o processo decisório. Somente por meio do conhecimento científico, amparado por métodos adequados, pode-se obter trazer efetiva contribuição para o entendimento da realidade (MASCARENHAS; ZABALDI; MORAES, 20II). Ter acesso às investigações, compreendê-las e propor outras, tudo isso também deve estar associado à competência do gestor. Além disso, interpretar e analisar resultados de estudos científicos se mostra crucial para o processo de inovação das práticas de gestão e da própria qualidade da assistência. $O$ exercício da pesquisa pode, ainda, romper com o reducionismo das abordagens tecnicistas e aproximar a reflexão da ação, na realidade local e na regional. Isso é essencial para evitar os equívocos da adoção de modelos de gestão baseados no senso comum e na repetição de práticas que já não trazem mais respostas aos problemas da população.

Comparando-se a média geral das com- petências técnicas $(4,0)$ com a das competências comportamentais $(4,4)$, observa-se que estas últimas apresentam uma diferença positiva de quatro décimos. Ou seja, enquanto as primeiras são consideradas 'muito importantes', as competências comportamentais estão numa posição intermediária, aproximando-se da condição de 'extremamente importantes'. Note-se que a competência técnica mais bem avaliada, 'Planejamento estratégico', obteve média 4,5, e a competência comportamental 'Ética', obteve média 4,7. Este resultado coincide com os posicionamentos de Freitas e Odelius (2017), Benevides, Santos e Dultra (2009) e Calhoun et al. (2008), que enfatizam a contribuição das competências comportamentais, ou seja, das habilidades e atitudes, para o aumento do diferencial competitivo das pessoas e das organizações.

\section{CONSIDERAÇÕES FINAIS}

A principal contribuição deste trabalho consistiu em apresentar a construção e validação de um instrumento quantitativo para a análise competências de gestores de serviços de saúde, uma categoria profissional que ainda é objeto de pouca investigação na literatura.

Os procedimentos de avaliação da confiabilidade e da validade interna mostraram elevada consistência e adequação das medições realizadas. Além disso, as dimensões retrataram os aspectos levantados na etapa exploratória, reforçando a validade de translação das medidas.

A análise dos resultados de cada eixo revelou que as competências técnicas relacionadas aos eixos 'Administração e contabilidade' e 'Política, planejamento e avaliação em saúde' são consideradas extremamente importantes para a formação do gestor, se- 
guidas das competências dos eixos 'Economia e demografia' e 'Gestão do trabalho e da educação'. No entanto, as competências relacionadas ao eixo 'Metodologias estruturantes' carecem de maior valorização, dado que elas têm o potencial de contribuir para o processo decisório. Diante da complexidade das atuais sociedades, torna-se fundamental promover a formação de um sujeito atuante e crítico no processo de busca de informações que precisam ser transformadas em conhecimentos. Neste caso, as metodologias estruturantes, que envolvem conhecimento de pesquisa, podem ser um recurso estratégico para a compreensão das diversas dimensões de fenômenos sociais, estabelecendo, dessa forma, uma relação transversal com os demais eixos temáticos. $A$ não valorização por parte da amostra pesquisada pode ser atribuída ao desconhecimento e pouca familiarização dos gestores com instrumentos dessa área de conhecimentos, passíveis de serem obtidas por meio de cursos de pósgraduação lato e stricto sensu.

Tal resultado revela a necessidade do gestor de compreender as políticas sociais e de saúde, o modo de funcionamento do sistema e dos serviços, assim como das organizações conectadas em rede, e saber avaliar os resultados obtidos, para que possa corrigir os desvios. O principal desafio imposto pelo atual cenário ao gestor, portanto, vincula-se, portanto, à transparência nos gastos dos recursos e ao modo de utilizar ferramentas e técnicas de planejamento e organização, a fim de elevar a eficácia das organizações e otimizar o uso dos recursos.
As competências comportamentais receberam médias superiores às técnicas. O desafio posto à formação do gestor em saúde, portanto, é romper com o paradigma cartesiano da educação formal, simplificante e centrado na transmissão de conhecimento, que resulta em uma gestão tecnicista, fragmentada e afastada da realidade. É preciso formar um gestor que entenda as reais necessidades dos usuários dos serviços que sua organização se propõe a atender.

É nesse sentido que ganha importância a formação multidisciplinar, orientanda pela lógica do desenvolvimento de competências efetivamente capazes de contribuir para transformar a realidade. Concorda-se com Santos e Honório (20I4) quando afirmam que na contemporaneidade as organizações exigem que o gestor abandone o papel tradicional e se mostre mais versátil, sabendo planejar e organizar o trabalho, de modo a obter resultados para as organizações.

Como limitação da pesquisa, apontam-se a heterogeneidade da formação dos sujeitos da pesquisa e a impossibilidade realizar uma seleção aleatória dos sujeitos. Desse modo, para futuros estudos, sugerem-se a ampliação e a definição de critérios que garantam maior representatividade à amostra, dada a diversidade de ocupações e de tipos de organizações de saúde que pertencem a uma mesma área da economia, mas possuem características estruturais e financeiras, dentre outras, bastante diversas. Por esta razão, recomenda-se a continuação de estudos sobre o tema investigado. 


\section{REFERÊNCIAS}

ALMEIDA, A. G.; BORBA, J. A.; FLORES, L. C. S.A utilização das informações de custos na gestão da saúde pública: um estudo preliminar em secretarias municipais de saúde do estado de Santa Catarina. Revista Administração Pública, n.3, v.43, p. 579-607, 2009. Disponível em: http://www.scielo. br/pdf/rap/v43n3/04.pdf. Acesso em: 3 de ago. 2019.

ALVES, L.C. et al. A influência das doenças crônicas na capacidade funcional dos idosos do Município de São P aulo, Brasil. Cadernos de Saúde Pública, Rio de Janeiro, v. 23, n. 8, p:1924-1930, 2007. Disponível em: http://www.scielo.br/ pdf/csp/v23n8/19.pdf. Acesso em: 3 de ago. 2019

$B A B B I E, E$. Métodos de pesquisas de survey. Belo Horizonte: Editora UFMG, 1999.

BARTH, M. et al. Developing key competencies for sustainable development in higher education. International Journal of Sustainability in Higher Education, v. 8, n. 4, p. 4I6-430, 2007. Disponível em: file:///Users/fernandogarcia/Downloads/SSRN -id1978290.pdf. Acesso em: 3 de ago. 2019.

BATISTA-SIQUEIRA, R. et al. Educação e competências para o SUS: é possível pensar alternativas à(s) lógica(s) do capitalismo tardio? Ciência \& Saúde Coletiva, v. I8, n. I, p. I59-I70, 20 I3. Disponível em: http://www.scielo.br/pdf/ csc/v18n I/I7.pdf. Acesso em: 3 de ago. 2019.

BENEVIDES, T.M.; SANTOS, J.S.; DULTRA, M.O.M. As competências profissionais mais requeridas no cenário das organizações baianas e suas relações com o construto modernidade organizacional. Re- vista de Administração FA-

CES Journal, v. 8, n. 4, p. 5I-78, 2009. Disponível em: http://www. fumec.br/revistas/facesp/article/ view/l64. Acesso em: 3 de ago. 2019.

BOYATZIS, R. E. Competencies in the 2 Ist Century. Journal of Management Development, v. $27 \mathrm{n}$. I, p. 5-I2, 2008. Disponível em: http://www.oostvoorncoaching. $\mathrm{nl} / \mathrm{wp}$-content/uploads/boyatzis-the+2 I st+century+competencies.pdf. Acesso em: 3 de ago. 2019.

BUCHAN, J.; DAL POZ, M. R. Skill mix in the health care workforce: reviewing the evidence. Bulletin of the World Health Organization, v.80, n. 7, p. 575-580, 2002. Disponível em: https://www.who. int/hrh/documents/skill_mix.pdf. Acesso em: 3 de ago. 2019.

CALHOUN, J.G. et al. Development of an interprofessional competency model for health care leadership. Journal of Healthcare Management, v. 53, n. 6, p.375389, 2008. Disponível em: http:// cahme.net/files/healthsector/ CalhounDevelopmentoflnterprofessionalCompetency.pdf. Acesso em: 3 de ago. 2019.

CARBONI, R.M.; REPPETTO, M.A. Uma reflexão sobre a assistência à saúde do idoso no Brasil. Revista Eletrônica de Enfermagem, v. 9, n. I, p. 25I-260, 2007. Disponível em: https://www.fen. ufg.br/revista/v9/n I/pdf/v9n l a 20. pdf. Acesso em: 3 de ago. 2019.

CARDOSO, O. O. ; SERRALVO. F. A. Pluralismo metodológico e transdisciplinaridade na complexidade: uma reflexão para a administração. Revista de Administração Pública - RAP, v. 43, n. I , p.49-66, 2009. Disponível em: http://www. scielo.br/pdf/rap/v43n l/a04v43nl. pdf.Acesso em: 3 de ago. 2019.

CHONG, E. Managerial competencies and career advancement: a comparative study of managers in two countries. Journal of Business Research, v. 66, p. 345-353, 2013. Disponível em: http://intra. pare.ee/files/Chong\%2020I3_kultuuride\%C3\%BClesed\%20kompetentsid_0.pdf. Acesso em: 3 de ago. 2019.

COSTA, F.J. Mensuração e desenvolvimento de escalas: aplicações em administração. Rio de Janeiro: Editora Ciência Moderna, $201 \mathrm{I}$.

DIAS H. C.; PAIVA, K. C. M. Competências do enfermeiro: estudo em um hospital privado. Revista Brasileira de Enfermagem, v.64, n. 3, p. 5II-520, 20।I. Disponível em: http://www.scielo.br/ pdf/reben/v64n3/v64n3a I5.pdf. Acesso em: 3 de ago. 2019.

FERNANDES, L. C.; MACHADO, R. Z.; ANSCHAU, G. O. Gerência de serviços de saúde: competências desenvolvidas e dificuldades encontradas na atenção básica. Ciência \& Saúde Coletiva, v. |4, Supl. I, p. I 54 I- I552, 2009. Disponível em: http://www.scielo.br/ $\mathrm{pdf} / \mathrm{csc} / \mathrm{vl} 4 \mathrm{~s}$ I/a28vl4sl.pdf. Acesso em: 3 de ago. 2019.

FRAGELLI, T. B. O.; SHIMIZU, H. E. Competências profissionais em saúde pública: conceitos, origens, abordagens e aplicações. Revista Brasileira de Enfermagem, v. 65, n.4, p. 667-74, 20I2. Disponível em: http://www.scielo.br/pdf/reben/v65n4/a I7v65n4.pdf. Acesso em: 3 de ago. 2019.

FREITAS, P.F.P.; ODELIUS, C. Escala de competências gerenciais em grupos de pesquisa. Revista de Administração FACES Journal, v. 
I6, n. 4, p. 45-65, 20।7. Disponível em: http://www.fumec.br/revistas/ facesp/article/view/4/34. Acesso em: 3 de ago. 2019.

GODOY, A. S.; D’AMÉLIO, M. Competências gerenciais desenvolvidas por profissionais de diferentes formações. Revista Organizações \& Sociedade, v. 19, n. 63, p. 621-639, 2012. Disponível em: http://www.scielo.br/pdf/osoc/ v19n63/v19n63a04.pdf. Acesso em: 3 de ago. 2019.

HAIR, J. F. et al. Multivariate data analysis. New York: Prentice Hall, 2010.

HILBERT, S. N.; DUARTE,T.A. E.; MILARÉ, S.A. Desenvolvendo competências em colaboradores da área da saúde. Boletim de Psicologia, v. 10, n. I25, p. 2|7-23।, 20|।. Disponível em: http://pepsic.bvsalud.org/ pdf/bolpsi/v6 In I35/v6 In I 35a08 pdf.Acesso em: 3 de ago. 2019.

HOKERBERG, Y.H.M. et al. O processo de construção de mapas de risco em um hospital público. Ciencia \& Saúde Coletiva, n. II, v. 2, p. 503-5।3, 2006. Disponível em: http://www.scielo.br/pdf/csc/ vl In2/30437.pdf. Acesso em: 3 de ago. 2019.

KLINE, R. B. Principles and practice of structural equation modeling. 2. ed. New York: The Guilford Press, 2005.

LASCHINGER, H.K.; SMITH, L. M. The influence of authentic leadership and empowerment on newgraduate nurses' perceptions of interprofessional collaboration. Journal Nursing Administration, v. 43, n. I, p. 24-29, 2013.

LE BOTERF, G. Desenvolvendo as competências dos profissionais. São Paulo: Bookman, 2003.

LEME, R. Aplicação pratica de gestão de pessoas por competências. Rio de Janeiro: Qualitymark, 2005. p. I29-I50.
MACKINNON, N.J. et al. Management competencies for canadian health executives: views from the field. Health Care Management Forum, v. I7, n 4, p. I 5-20, 2004.

MALIK, A. M.; TELES, J. P. Hospitais e programas de qualidade no Estado de São Paulo. RAE - Revista de Administração de Empresas, São Paulo, v. 4I, n.3, p. 5I-59, 200I. Disponível em: http://www. scielo.br/pdf/rae/v4 In3/v4In3a06. pdf. Acesso em: 3 de ago. 2019.

MANENTI, S.A. et al. O processo de construção do perfil de competências gerenciais para enfermeiros coordenadores de área hospitalar. Revista da Escola de Enfermagem da USP, v. 46, n. 3, p.727-733, 20I2. Disponível em: http://www.scielo.br/pdf/reeusp/ v46n3/27.pdf. Acesso em: 3 de ago. 2019 .

MANFREDI, S. M. Trabalho, qualificação e competência profissional: das dimensões conceituais e políticas. Educação \& Sociedade, v. 19, n. 64, p. 13-49, 1999. Disponível em: http://www.scielo.br/scielo.php?script $=$ sci_arttext\&pid= S0I0I-7330I998000300002\&In$\mathrm{g}=$ en\&nrm=iso\&tlng=pt. Acesso em: 3 de ago. 2019 .

MASCARENHAS A. O.; ZAMBALDI, F.; MORAES, E. A. Rigor, relevância e desafios da academia em administração: tensões entre pesquisa e formação profissional. RAE Revista de Administração de Empresas, v. 5I, n. 3, p. 265-279, 20I I. Disponível em: http://www. scielo.br/pdf/rae/v5 In3/v5 In3a07. pdf.Acesso em: 3 de ago. 2019.

MCCLELLAND, D. C. Testing for competence rather than intelligence. American Psychologist, v. 28, p. I-4, 1973. Disponível em: https://www.therapiebreve.be/ documents/mcclelland-1973.pdf. Acesso em: 3 de ago. 2019.
MUTHEN, B.; KAPLAN, D. A comparison of some methodologies for the factor analysis of non-normal Likert variables: a note on the size of the model. British Journal of Mathematical and Statistical Psychology, v. 45, n. I, p. 19-30, 1992. Disponível em: file:///Users/ fernandogarcia/Downloads/eScholarship\%20UC\%20item\%20 49m7794d.pdf. Acesso em: 3 de ago. 2019.

NETEMEYER, R. G.; BEARDEN,W. O.; SHARMA, S. Scaling procedures: issues and applications. New York: Sage Publications, 2003.

NOGUEIRA S.L.; GERALDO, J.M.; MACHADO, J.C.; RIBEIRO, R.C.L. Distribuição espacial e crescimento da população idosa nas capitais brasileiras de 1980 a 2006: um estudo ecológico. Revista Brasileira de Estudos Populacionais, São Paulo, v. 25, n. I, p. 195-198, 2008. Disponível em: http://www.scielo. br/pdf/rbepop/v25n l/v25nla l2.pdf. Acesso em: 3 de ago. 2019.

NUNES, S. C.; BARBOSA, A.B.Q. Formação baseada em competências ? Um estudo em cursos de graduação em administração. Revista de Administração Mackenzie, v. 10, n.5, p. 28-52, 2009. Disponível em: http://www.scielo.br/pdf/ram/ vI0n5/vIOn5a03.pdf.Acesso em: 3 de ago. 2019.

PASQUALI, L. Instrumentação psicológica: fundamentos e práticas. Porto Alegre:Artmed, 2010.

PERERA, F. P. R.; PEIRÓ, M. Strategic planning in healthcare organizations. Revista Espanhola de Cardiologia, v. 65, n. 8, p. 794754, 20 I2. Disponível em: https:// www.revespcardiol.org/en-pdf-SI8855857I200I82X. Acesso em: 3 de ago. 2019 .

PERRENOUD, P. Dez competências para ensinar. Porto Alegre: Artes Médicas, 2014. 
RUAS, R. L. et al. A dinâmica das competências organizacionais e a contribuição da aprendizagem: um estudo de caso no setor bancário. Revista Alcance, v. 2I, n, 4, p. 6I2-649, 2014. Disponível em: http://www.redalyc. org/pdf/4777/477747 I65003.pdf. Acesso em: 3 de ago. 2019.

SANTOS, E. P.; HONÓRIO, L. C. Competências gerenciais em uma rede mineira de farmácias. Revista Alcance, 2 I, n, 4, p. 612 649, 2014. Disponível em: https:// siaiap32.univali.br/seer/index. php/ra/article/view/4952/pdf_42. Acesso em: 3 de ago. 2019.

SEIXAS, M.A. S.; MELO, H.T. de. Desafios do administrador hospitalar. Revista Gestão \& Planeja- mento, v. 5, n. 9, p. 16-20, 2004. Disponível em: https://revistas. unifacs.br/index.php/rgb/article/ viewFile//85//88.L. Acesso em: 3 de ago. 2019.

SCHOUT, D.; NOVAES, H. M. D. Do registro ao indicador: gestão da produção da informação assistencial nos hospitais. Ciência \& Saúde Coletiva, v. I2, n. 4, p. 935-44, 2007. Disponível em: http://www. scielo.br/pdf/csc/vI2n4/I2.pdf. Acesso em: 3 de ago. 2019.

SODERQUIST, K. E. et al. From task -based to competency-based: a typology and process supporting a critical HRM transition. Personnel Review, v. 39, n.3, p. 325346, 2010.

TABACHNICK, B. G.; FIDELL, L. S.
Using multivariate statistics. 5. ed. Boston: Pearson/Allyn \& Bacon, 2007.

VILASBOAS, A. L. Q.; PAIM, J. S. Práticas de planejamento e implementação de políticas no âmbito municipal. Cadernos de Saúde Pública, v. 24, n.6, p. 1239-1250, 2008. Disponível em: http://www. scielo.br/pdf/csp/v24n6/05.pdf. Acesso em: 3 de ago. 2019.

VINZI,V. E.;TRINCHERA, L.;AMATO, S. Handbook of Partial Least Squares. Berlin, Heidelberg: Springer Berlin Heidelberg, 2010.

ZARIFIAN, P. Compétences et stratégies d'entreprise: les démarches compétences à l'épreuve de la stratégie de grandes entreprise. Paris: Éditions Liaisons, 2005. 